\title{
Assessment of Left Ventricle Diastolic Dysfunction in Chronic Kidney Disease Patients
}

\author{
Shady Elhusseiny
}

Department of cardiology, faculty of medicine, Mansoura University, Egypt.

Correspondence to: Shady Elhusseiny, Department of cardiology, faculty of medicine, Mansoura University, Egypt.

Email:

shadycardiology@gmail.com

Received: 15 June 2020

Accepted: 19 January 2021

\begin{abstract}
:
Introduction: Cardiovascular disease (CVD) remains the most common cause of mortality in chronic kidney disease (CKD). Objective: to determine the prevalence and quantify the relation of LV diastolic dysfunction and CKD. Methods: Prospective study carried on 100 patients (ages: 20-86 years) with CKD, divided into 4 groups according to their estimated glomerular filtration rate (eGFR): i) Group 1: GFR=60-89 (12 patients), ii) Group 2: GFR=30-59 (33 patients), iii) Group 3: GFR=15-29 (33 patients) and iv) Group 4: GFR $<15$ or on dialysis (22 patients) and 20 healthy subjects (ages: 50-75 years) as control group referred the department of Cardiology- Faculty of Medicine- Mansoura University, for routine evaluation during the period from October 2017 to June 2018. Conventional pulsed wave Doppler (cPWD) echocardiography and tissue Doppler imaging (TDI) were performed in all patients Results: Comparison of the 4 groups of CKD patients regarding grades of LV diastolic dysfunction; grades II \& III, LV diastolic dysfunction were more prevalent among patients of group 3 and group 4 CKD patients $(\mathrm{p}<0.001)$, concerning correlation between GFR and echocardiographic parameters in the study
\end{abstract} population; there was significant direct correlation between GFR and E/MED E' (R: 0.42; P<0.001) and Lat E' (R: 0.30; $\mathrm{P}=0.001)$, While there was significant inverse correlation between GFR and LA size ( $\mathrm{R}:-0.21 ; \mathrm{P}=0.018), \mathrm{E} / \mathrm{A}(\mathrm{R}:-0.19 ; \mathrm{P}=0.029), \mathrm{E}(\mathrm{R}:-0.49 ; \mathrm{P}<0.001)$, E/LAT E'(R: -0.53; $\mathrm{P}<0.001)$ and grades of diastolic dysfunction $(\mathrm{R}:-0.54 ; \mathrm{P}<0.001)$.Conclusion: $\mathrm{LV}$ diastolic dysfunction is an indicator of damage to the myocardium before heart failure becomes clinically apparent.

Key words: Chronic kidney disease, left ventricle diastolic dysfunction, tissue doppler imaging. 



\section{Introduction}

Diastolic function is an important element of cardiac function. The ventricle must fill properly to eject enough stroke volume, required by the body ${ }^{(1)}$.

In the past, heart failure with preserved Ejection Fraction (HFpEF) was known as Diastolic heart failure. Although, this term was proved to be inaccurate, as the physiological abnormalities are not only restricted to Diastole ${ }^{(2)}$

The most important component sharing in diastolic dysfunction are left ventricular diastolic stiffness and left ventricular relaxation impairment ${ }^{(3)}$.

Diastolic function can be evaluated through laboratory measures (BNP and NT pro BNP), invasive methods (Catheterization) and noninvasive methods (Echocardiography) ${ }^{(4)}$.

The assessment of left ventricular diastolic function non-invasively has become increasingly important for many reasons: 1) early detection and assessment of the severity of impairment of active relaxation may lead to application of preventive measures to delay or avoid the occurrence of clinical heart failure $^{(5)}$, 2) Diastolic dysfunction may point the earliest manifestation of myocardial ischemia, 3) In addition, diastolic dysfunction is present in 44 percent of hypertensive, diabetic, obese patients ${ }^{(6)}$

Echocardiography is considered the method of choice when evaluating left ventricular diastolic function ${ }^{(7)}$.

Finally, the European-working group defines HFpEF as: a- Symptoms and signs of congestive heart failure, b- Left ventricular ejection fraction (LVEF) $>50 \%$ and nondilated left ventricle less than $97 \mathrm{ml} / \mathrm{m} 2$, cEvidence of increased left ventricular filling pressure; either: 1- Pulmonary capillary wedge pressure (PCWP) more than $12 \mathrm{mmHg}$ or left ventricular end diastolic pressure more than $16 \mathrm{mmHg}, 2-\mathrm{E} / \mathrm{e}^{\prime}>15,3-\mathrm{E} / \mathrm{e}^{\prime}>8$ but $<$ 15 and a positive $\mathrm{B}$ natriuretic peptide BNP > $200 \mathrm{pg} / \mathrm{ml}$ or NT-BNP > $220 \mathrm{pg} / \mathrm{ml}^{(\underline{8})}$.

Patients with chronic kidney disease (CKD) have a high burden of conventional risk factors that are closely related to accelerated atherosclerosis, left ventricular (LV) dilatation with hypertrophy, systolic dysfunction, and high LV filling pressure. ${ }^{(9)}$.

Our study aimed to determine the prevalence and quantify the relation of LV diastolic dysfunction in CKD patients. 


\section{Materials and methods}

Data analyzed in this prospective observational comparative study were obtained from patients with CKD and normal healthy subjects who were referred to cardiology department Mansoura University for routine evaluation during the period from October 2017 to June 2018 after approval of the local ethical committee of Faculty of Medicine, Mansoura University.

The diagnosis of CKD was based on evidence of structural or functional kidney abnormalities (abnormal urine analysis or imaging studies) that persist for at least three months, with or without a decreased glomerular filtration rate (GFR) (as defined by a GFR of less than $60 \mathrm{~mL} / \mathrm{min}$ per 1.73 m2) according to the National Kidney Foundation Kidney Disease Outcomes Quality Initiative (NKF/KDOQI) working group definition $\stackrel{(10)}{ }$.

The following patients are excluded from our study: Patients with ischemic heart disease, congenital heart disease, valvular heart disease, primary myocardial disease, reduced $\mathrm{EF} ;<50 \%$ and chronic obstructive pulmonary disease.

After considering the exclusion criteria, the number of patients remain is $100 \mathrm{CKD}$ patients (Age 20-86 years) who were divided according to GFR estimated by CockcroftGault equation of creatinine clearance into 4 groups as test groups: i) Group 1: GFR $=60$ 89 (12 patients), ii) Group 2: GFR $=30-59$ (33 patients), iii) Group 3: GFR $=15-29$ (33 patients), iv) Group 4: GFR $<15$ or on dialysis ( 22 patients) in addition to 20 healthy subjects (ages: 50-75 years) as control group.

Patients who met the inclusion criteria and gave informed consent to participate in the study, were subjected to:

I) Full history taking with emphasis on cardiovascular disease risk factors as hypertension, Diabetes, dyslipidemia, cigarette smoking; Hypertension was defined according to Eighth Joint National Committee (JNC8) by persistent resting systolic blood pressure > $140 \mathrm{mmHg}$, diastolic blood pressure $>90 \mathrm{~mm} \mathrm{Hg}$, or current treatment with blood pressure-lowering medications $\stackrel{(11)}{ }$, Diabetes was defined by prior diagnosis with current antidiabetic medications. Criteria for the diagnosis of diabetes according to American Diabetes Association (ADA) include any of the following: 1) A hemoglobin $\mathrm{A} 1 \mathrm{C}(\mathrm{HbA} 1 \mathrm{c})$ level of $\geq 6.5 \% ; 2$ ) A fasting plasma glucose (FPG) level $\geq 126$ $\mathrm{mg} / \mathrm{dL}$; 3) 2-h plasma glucose $\geq 200 \mathrm{mg} / \mathrm{dl}$ during an oral glucose tolerance test (OGTT). 4) A random plasma glucose $\geq 200 \mathrm{mg} / \mathrm{dL}$ in 
a patient with classic symptoms of hyperglycemia ${ }^{(12)}$, Dyslipidemia was defined by prior diagnosis with current cholesterollowering medications, or fasting serum cholesterol, low density lipoprotein (LDL) and high density lipoprotein (HDL) cholesterol, triglycerides levels were >200 $\mathrm{mg} / \mathrm{dl},>100 \mathrm{mg} / \mathrm{dl}$ and $<40 \mathrm{mg} / \mathrm{dl},>150$ $\mathrm{mg} / \mathrm{dl}$ respectively ${ }^{(13)}$ and Smokers were defined as current smokers, and ex-smokers were defined as patients whom quiet smoking more than 6 months.

II) Clinical examination with emphasis on pulse, blood pressure, neck viens, basal lung crepitation and local cardiac examination.

III) Biochemical assessment: Blood glucose, serum creatinine, complete blood count (CBC), INR and urine analysis values of each patient were recorded.

IV) 12 lead surfaceECG: was done for all included patients.

V) Echocardiography: Patients were imaged in the left lateral decubitus position using a commercially available system General Electric Vivid E9 XD clear Dimensions ultrasound system (GE Healthcare, USA) using the M5Sc transducer, Images were obtained with a simultaneous ECG signal recorded.
Conventional echo study: 2D images were obtained during breath hold and saved in cine-loop format from three consecutive beats, 2D guided M-Mode and Doppler Echocardiography technique (pulsed wave) were done and images were acquired in different views [apical views - parasternal long axis - parasternal short axis].

M-mode \& 2-D echo: For assessment left ventricle internal dimensions (LVIDs); $\{$ End systolic dimension (ESD); Normal: $47.86 \pm$ $4.3 \mathrm{~mm} \&$ End diastolic dimension (EDD); Normal: $30.42 \pm 3.7 \mathrm{~mm}$ \}, LV global function \{Ejection fraction $(\mathrm{EF})$; Normal: $69.14 \pm 6.83$, Fractional shortening (FS); Normal: $36.48 \pm 4.81\}^{(14)}$, The references for measured values were according to European society of cardiology.

Pulsed-wave Doppler echo: By using pulsed wave (PW) on mitral valve, the following were measured in 10 consecutive cycles and mean was calculated: 1) $\mathrm{E}$ wave: peak $\mathrm{E}$ wave, is measured by placing a $2 \mathrm{~mm}$ sample volume on mitral leaflet tip in apical-4 chamber view, 2) A wave: peak A wave, is measured by placing a $2 \mathrm{~mm}$ sample volume on mitral leaflet tip in apical-4 chamber view, 3) Transmitral deceleration time (E-DT): it is the time for peak $E$ velocity to turn back to baseline; In normal, the value range between 160-260 msec and 4) Isovolumic relaxation 
time (IVRT): It is the time between opening of aortic valve and closure of mitral valve. It is measured by placing pulsed wave Doppler in left ventricular outflow tract close to anterior mitral valve leaflet to record both velocities in apical view; 60-100 $\mathrm{msec}$ is considered normal ${ }^{(15)}$.

Tissue Doppler Imaging: It is done by placing a $5 \mathrm{~mm}$ sample volume over lateral mitral annulus then the aliasing velocity should be advanced to $20 \mathrm{~cm} / \mathrm{sec}$ for signal optimization (16), from tissue Doppler imaging (TDI), the following were obtained: 1) $\mathrm{E}^{\prime}$ wave: Reflect rate of myocardial relaxation. It is better than transmitral E velocity as it is preload independent and not affected by left atrial pressure (LAP). Value $\geq 8 \mathrm{~cm} / \mathrm{sec}$ represents normal relaxation and value $<8 \mathrm{~cm} / \mathrm{sec}$ represent impaired relaxation $\left.{ }^{(4)}, 2\right)$ E/e' ratio: It reflects filling pressure, values i) $<8$ reflects normal PCWP and normal diastolic function, ii) > 15 using lateral annulus reflects increased PCWP and abnormal diastolic function ${ }^{(15)}$ and iii) 8 - 15 must be evaluated by other Echo parameters.

Generally, normal young individuals with normal cardiac diastolic function have normal E/A ratio $>1$, IVRT $<100 \mathrm{msec}, \mathrm{DT}=160-$ $260 \mathrm{msec}$, pulmonary S/D ratio > 1 , pulmonary Atrial reversal wave $(\mathrm{AR})<35$ $\mathrm{cm} / \mathrm{sec}$, tissue Doppler mitral annular velocity (E') $>8 \mathrm{~cm} / \mathrm{sec}, \mathrm{E} / \mathrm{e}^{\prime}<8^{(4)}$.

Stages of cardiac diastolic dysfunction:

1) Stage I (Impaired relaxation): Characterized by E/A ratio $<1$, prolonged IVRT > $100 \mathrm{msec}$, prolongation of DT slope $>260 \mathrm{msec}$, normal pulmonary venous S/D ratio, TDIE' $^{\prime}<8 \mathrm{~cm} / \mathrm{sec}, \mathrm{E} / \mathrm{e}^{\prime}>15$ at rest or with exercise ${ }^{(15)}$,

2) Stage II (Pseudonormal Filling pattern): trans mitral flow pattern (E/A ratio, DT, IVRT) return to normal values, Pseudo normal pattern can be differentiated by: i) suspicion of the condition; normal trans mitral flow in the setting of LVH or systolic dysfunction is mostly pseudo normal, ii) estimate left atrial size followed by estimation of filling pressure (E/e'). iii) only in case of systolic dysfunction; effect of Valsalva maneuver, blunting of pulmonary venous $S$ wave and the flow propagation velocity $<50$ $\mathrm{cm} / \mathrm{sec}^{(15)}$,

3) Stage III/IV (Restrictive pattern): Characterized by marked increase in $\mathrm{E}$ velocity, E/A ratio $>2$, short DT time $<150$ msec, short IVRT $<70 \mathrm{msec} \stackrel{(15)}{ }$, the systolic forward flow velocity in pulmonary vein is decreased due to increased LAP and decreased compliance of left atrial. Tissue Doppler $\mathrm{E}^{\prime}$ is $<8 \mathrm{~cm} / \mathrm{sec}$ with E/e' ratio $>15$ 
(16) , the presence of reversibility (reverse the filling pattern to grade 1 or 2 dysfunction with Valsalva maneuver or after diuresis) and

4) Stage IV/IV (Restrictive pattern): Failure of reversal means grade IV dysfunction (14).

\section{Statistical analysis}

Data management and statistical analysis were performed using Statistical Package for Social Sciences (SPSS) vs. 21(Chicago, Ill, USA).

Numerical data were summarized using means and standard deviations and ranges. Categorical data were summarized as numbers and percentages. Comparisons between the 4 groups with respect to normally distributed numeric variables were done using the t-test. For categorical variables, differences were analyzed with $\chi^{2}$ (chi square) test and Fisher's exact test when appropriate.

Pearson Correlation between variables was done, "r" (Pearson correlation coefficient) ranges from +1 to -1 . A value of 0 indicates that there is no association between the two variables; a value greater than 0 indicates a positive association; a value less than 0 indicates a negative association.

\section{Level of significance:}

For all above mentioned statistical tests done, the threshold of significance is fixed at $5 \%$ level ( $\mathrm{p}$-value). The results were considered: Non-significant when the probability of error is more than $5 \%(\mathrm{p}>0.05)$, Significant when the probability of error is less than $5 \%$ (p $\leq$ 0.05), highly significant when the probability of error is less than $0.1 \%(p \leq 0.001)$; the smaller the p-value obtained, the more significant are the results.

\section{Results}

During the study period 100 consecutive patients with $\mathrm{CKD}$ referred to us for routine evaluation were divided according to GFR into 4 groups as test groups: i) Group 1: GFR $=60-89$ (12 patients), ii) Group 2: GFR $=30$ - 59 (33 patients), iii) Group 3: GFR = $15-$ 29 (33 patients), iv) Group 4: GFR < 15 or on dialysis (22 patients) (Table 1) in addition to 20 healthy subjects as control group (Table I)..

The baseline demographic characteristics and risk factors of the studied groups are listed in Table 2. We observed high significant difference between the five groups regarding age $(\mathrm{P}<0.001)$ while there was no significant difference regarding sex distribution $(\mathrm{P}=$ 0.385) (Table 2) 
There were significant differences between the studied groups as regard DM, smoking, hypertension and increased body mass index (BMI): These risk factors were more identified in CKD patient groups compared to control group with more prevalence in group 4 patients than other groups $(68.2 \%$; $\mathrm{P}<$ $0.001,63.6 \% ; \mathrm{P}=0.002,72.7 \% ; \mathrm{P}=0.014$ and 28.5; $\mathrm{P}<0.001$ ), otherwise there was no significant difference between the studied groups as regard hypercholesterolemia $(\mathrm{P}=$ 0.318) as shown in (Table 2).

We reported significant difference between five groups regarding LA size which is more dilated in groups $3 \& 4$ versus groups 1, 2 and control group (4.11\& 3.98 versus $3.69,3.77$ and 3.61 respectively; $\mathrm{P}=0.002$ ), $\mathrm{DT}$ time which is more prolonged in groups $2 \& 3$ versus groups 1, 4 and control (236.5 \& 228.2 versus $190.2,196$ and 187.9 respectively; $\mathrm{P}=$ 0.0001), E/A which was less than 1 in groups 2, 3 and control versus more than 1 in groups $1 \& 4(0.84,0.91$ and 0.82 versus $1.01 \& 1.32$ respectively; $\mathrm{P}=0.0001), \mathrm{E}(\mathrm{P}=0.0001)$, MED E' which was significantly reduced in group 4 versus groups 1, 2, 3 and control (0.08 versus $0.09,0.09,0.09$ and 1.11 respectively; $\mathrm{P}=0.001)$, E/MED E' which was more significantly increased in group 4 when compared to groups $1,2,3$ and control (12.3 versus $6.86, \quad 7.74, \quad 8.65$ and 7.5 respectively; $\mathrm{P}=0.0001)$, Lat $\mathrm{E}^{\prime}$ which was significantly reduced in group 4 versus groups $1,2,3$ and control (0.08 versus $0.1,0.1,0.1$ and 0.11 respectively; $\mathrm{P}=0.001), \mathrm{EF}(\mathrm{P}=$ 0.021) and E/LAT E' which was more significantly increased in group 4 when compared to groups 1, 2, 3 and control (12.1 versus 5.8, 7.2, 7.9 and 6.9 respectively; $\mathrm{P}=$ 0.0001) (Table 3)

There was significant difference between the four test groups regarding the grades of diastolic dysfunction which was significantly increased among patients of groups $3 \& 4$, grade II diastolic dysfunction accounts for $18.2 \% \& 40.9 \%$ of groups $3 \& 4$ patients respectively, grade III diastolic dysfunction accounts for $3.1 \% \& 18.2 \%$ of groups $3 \& 4$ patients respectively and no reported cases of grades II \& III diastolic dysfunction in groups $1 \& 2$ patients $(\mathrm{P}<0.001)$ (Table 4$)$

Concerning correlation between GFR and echocardiographic parameters in the studied patients; there was significant direct correlation between GFR and E/MED E' $(\mathrm{R}=$ $0.42 ; \mathrm{P}<0.001)$ and Lat $\mathrm{E}^{\prime}(\mathrm{R}=0.30 ; \mathrm{P}=$ 0.001). While there was significant inverse correlation between GFR and LA size $(\mathrm{R}=$ $0.21 ; \mathrm{P}<0.018), \mathrm{E} / \mathrm{A}(\mathrm{R}=-0.19 ; \mathrm{P}=0.029)$, $\mathrm{E}(\mathrm{R}=-0.49 ; \mathrm{P}<0.001), \mathrm{E} / \mathrm{LAT} \mathrm{E}^{\prime}(\mathrm{R}=-$ $0.53 ; \mathrm{P}<0.001)$ and grades of diastolic dysfunction $(\mathrm{R}=-0.54 ; \mathrm{P}<0.001)($ Table 5) 
Table 1: Distribution of the study population regarding GFR group:

\begin{tabular}{lcccccc}
\hline & Group 1 & Group 2 & Group 3 & Group 4 & $\chi^{2}$ & P-value \\
\hline No & 12 & 33 & 33 & 22 & 12.2 & $0.007^{*}$ \\
$\%$ & $12 \%$ & $33 \%$ & $33 \%$ & $22 \%$ & & \\
\hline$\chi^{2}:$ chi square test; *: significant $p<0.05 ;$ No: number; $\%:$ percent. &
\end{tabular}

Table 2: Baseline demographic data and risk factors of the study population among five groups:

\begin{tabular}{|c|c|c|c|c|c|c|c|c|}
\hline & & $\begin{array}{l}\text { Group } 1 \\
(\mathrm{No}=12)\end{array}$ & $\begin{array}{l}\text { Group } 2 \\
(\mathrm{No}=33)\end{array}$ & $\begin{array}{l}\text { Group } 3 \\
(\mathrm{No}=33)\end{array}$ & $\begin{array}{l}\text { Group } 4 \\
(\mathrm{No}=22)\end{array}$ & $\begin{array}{l}\text { Control } \\
(\mathrm{No}=20)\end{array}$ & $\begin{array}{l}\text { Significance } \\
\text { test }\end{array}$ & P-value \\
\hline \multirow{2}{*}{$\begin{array}{l}\text { Age } \\
\text { (years) }\end{array}$} & Mean \pm SD & $51.4 \pm 15.1$ & $61.1 \pm 9.6$ & $68 \pm 6$ & $75.3 \pm 8.3$ & $62.5 \pm 12.5$ & \multirow{2}{*}{$F=16.4$} & \multirow{2}{*}{$<0.001 *$} \\
\hline & Range & $20-65$ & $29-80$ & $58-85$ & $45-86$ & $50-75$ & & \\
\hline \multirow{4}{*}{ Sex } & Male & 8 & 18 & 12 & 10 & 9 & \multirow{4}{*}{$\chi^{2}=4.2$} & \multirow{4}{*}{0.385} \\
\hline & $(\%)$ & $(66.7 \%)$ & $(54.5 \%)$ & $(36.4 \%)$ & $(45.5 \%)$ & $(45 \%)$ & & \\
\hline & Female & 4 & 15 & 21 & 12 & 11 & & \\
\hline & \multirow[t]{2}{*}{$(\%)$} & $(33.3 \%)$ & $(45.5 \%)$ & $(63.6 \%)$ & $(44.5 \%)$ & $(55 \%)$ & & \\
\hline & & 5 & 18 & 17 & 16 & 4 & $\chi^{2}=12.4$ & $0.014 *$ \\
\hline \multirow{2}{*}{\multicolumn{2}{|c|}{ Hypertension }} & $(41.7 \%)$ & $(54.5 \%)$ & $(51.5 \%)$ & $(72.7 \%)$ & $(20 \%)$ & & \\
\hline & & 6 & 10 & 6 & 14 & 3 & $\chi^{2}=17.3$ & $0.002 *$ \\
\hline \multirow{2}{*}{\multicolumn{2}{|c|}{ Smoking }} & $(50 \%)$ & $(30.3 \%)$ & $(18.2 \%)$ & $(63.6 \%)$ & $(15 \%)$ & & \\
\hline & & 1 & 3 & 8 & 2 & 2 & $\chi^{2}=4.7$ & 0.318 \\
\hline \multirow{2}{*}{\multicolumn{2}{|c|}{ Hypercholesterelemia }} & $(8.3 \%)$ & $(9.1 \%)$ & $(24.2 \%)$ & $(9.1 \%)$ & $(10 \%)$ & & \\
\hline & & 2 & 7 & 12 & 15 & 3 & $\chi^{2}=19.1$ & $<0.001 *$ \\
\hline \multicolumn{2}{|c|}{ Diabetes mellitus } & $(16.7 \%)$ & $(21.2 \%)$ & $(36.4 \%)$ & $(68.2 \%)$ & $(15 \%)$ & & \\
\hline \multicolumn{2}{|c|}{ BMI (kg/m2) } & $22.3 \pm 1.3$ & $23.5 \pm 3.6$ & $25.4 \pm 3.1$ & $28.5 \pm 4.2$ & $23.4 \pm 1.6$ & $\mathrm{~F}=12$ & $<0.001 *$ \\
\hline
\end{tabular}

$\chi^{2}$ : chi square test; F: Fischer exact test; *: significant $p$ <0.05; No: number; SD: standard deviation; BMI: body mass index. 
Table 3: Echocardiographic parameters among five groups:

\begin{tabular}{|c|c|c|c|c|c|c|c|c|}
\hline & & $\begin{array}{l}\text { Group l } \\
(\mathrm{No}=12)\end{array}$ & $\begin{array}{l}\text { Group } 2 \\
(\mathrm{No}=33)\end{array}$ & $\begin{array}{l}\text { Group } 3 \\
(\mathrm{No}=33)\end{array}$ & $\begin{array}{l}\text { Group } 4 \\
(\mathrm{No}=22)\end{array}$ & $\begin{array}{l}\text { Control } \\
(\mathrm{No}=20)\end{array}$ & $\mathbf{F}$ & $\begin{array}{l}P \text { - } \\
\text { value }\end{array}$ \\
\hline $\mathbf{E F}$ & Mean \pm SD & $66.2 \pm 6.5$ & $65.2 \pm 7$ & $66.4 \pm 8.2$ & $65.8 \pm 9.7$ & $72.2 \pm 5$ & \multirow{2}{*}{3} & \multirow{2}{*}{$0.021 *$} \\
\hline$(\%)$ & Range & $56-79$ & $52-87$ & $52-89$ & $50-87$ & $59-80$ & & \\
\hline \multirow{2}{*}{ LA size } & Mean \pm SD & $3.69 \pm 0.29$ & $3.77 \pm 0.53$ & $4.11 \pm 0.51$ & $3.98 \pm 0.58$ & $3.61 \pm 0.22$ & \multirow{2}{*}{4.6} & \multirow{2}{*}{$0.002 *$} \\
\hline & Range & $3.2-4.3$ & $2.6-5.2$ & $3.2-5.2$ & $2.8-5.3$ & $3.1-4$ & & \\
\hline \multirow{2}{*}{ DT time } & Mean \pm SD & $190.2 \pm 31.2$ & $236.5 \pm 52.3$ & $228.2 \pm 41.5$ & $196 \pm 49.3$ & $187.9 \pm 32.1$ & \multirow{2}{*}{6.5} & \multirow{2}{*}{$0.0001 *$} \\
\hline & Range & $126-234$ & $148-458$ & $130-330$ & $120-290$ & $126-234$ & & \\
\hline \multirow{2}{*}{ E/A } & Mean \pm SD & $1.01 \pm 0.36$ & $0.84 \pm 0.32$ & $0.91 \pm 0.29$ & $1.32 \pm 0.64$ & $0.82 \pm 0.21$ & \multirow{2}{*}{9.4} & \multirow{2}{*}{$0.0001 *$} \\
\hline & Range & $0.55-1.75$ & $0.33-1.6$ & $0.4-1.9$ & $0.65-2.75$ & $0.55-1.2$ & & \\
\hline \multirow{2}{*}{$\mathbf{E}$} & Mean \pm SD & $0.6 \pm 0.14$ & $0.65 \pm 0.18$ & $0.75 \pm 0.16$ & $0.93 \pm 0.17$ & $0.73 \pm 0.07$ & \multirow{2}{*}{13.5} & \multirow{2}{*}{$0.0001 *$} \\
\hline & Range & $0.4-0.8$ & $0.3-1.11$ & $0.4-1.05$ & $0.7-1.4$ & $0.61-0.84$ & & \\
\hline \multirow{2}{*}{ MED E' } & Mean \pm SD & $0.09 \pm 0.02$ & $0.09 \pm 0.03$ & $0.09 \pm 0.02$ & $0.08 \pm 0.03$ & $0.11 \pm 0.03$ & \multirow{2}{*}{3.5} & \multirow{2}{*}{$0.01 *$} \\
\hline & Range & $0.06-0.13$ & $0.04-0.15$ & $0.05-0.12$ & $0.03-0.15$ & $0.6-0.16$ & & \\
\hline \multirow{2}{*}{ E/MED E' } & Mean \pm SD & $6.86 \pm 2.1$ & $7.74 \pm 3.48$ & $8.65 \pm 2.38$ & $12.3 \pm 4.71$ & $7.5 \pm 2.3$ & \multirow{2}{*}{9.3} & \multirow{2}{*}{$0.0001 *$} \\
\hline & Range & $3.63-11.6$ & $2.6-20$ & $4.4-15$ & $6.7-25$ & $4.4-12.7$ & & \\
\hline \multirow{2}{*}{ LAT E' } & Mean \pm SD & $0.1 \pm 0.02$ & $0.1 \pm 0.03$ & $0.1 \pm 0.02$ & $0.08 \pm 0.02$ & $0.11 \pm 0.02$ & \multirow{2}{*}{4.8} & \multirow{2}{*}{$0.001 *$} \\
\hline & Range & $0.08-0.14$ & $0.05-0.17$ & $0.05-0.15$ & $0.04-0.12$ & $0.08-0.14$ & & \\
\hline \multirow[t]{2}{*}{ E/LAT E' } & Mean \pm SD & $5.8 \pm 1.04$ & $7.2 \pm 3$ & $7.9 \pm 2.8$ & $12.1 \pm 3$ & $6.9 \pm 1.26$ & \multirow{2}{*}{17.3} & \multirow{2}{*}{$0.0001 *$} \\
\hline & Range & $4.35-7.77$ & $2.35-16$ & $4.2-17.5$ & $7.63-18.75$ & $4.7-9.8$ & & \\
\hline
\end{tabular}

F: Fischer exact test; *: significant $p<0.05 ;$ SD: standard deviation; EF: ejection fraction; LA: left atrium; DT: deceleration time; MED: medial; LAT: lateral.

Table 4: Diastolic dysfunction among four groups:

\begin{tabular}{|c|c|c|c|c|c|c|c|}
\hline & & $\begin{array}{l}\text { Group l } \\
(\mathrm{No}=12)\end{array}$ & $\begin{array}{l}\text { Group } 2 \\
(\mathrm{No}=33)\end{array}$ & $\begin{array}{l}\text { Group } 3 \\
(\mathrm{No}=33)\end{array}$ & $\begin{array}{l}\text { Group } 4 \\
(\mathrm{No}=22)\end{array}$ & $\chi^{2}$ & P-value \\
\hline \multirow{4}{*}{$\begin{array}{l}\text { Diastolic } \\
\text { dysfunction }\end{array}$} & No & $6(50 \%)$ & $8(24.2 \%)$ & $2(6.1 \%)$ & $0(0 \%)$ & 45.9 & $<0.001 *$ \\
\hline & Grade I & $6(50 \%)$ & $25(75.8 \%)$ & $24(72.7 \%)$ & $9(40.9 \%)$ & & \\
\hline & Grade II & 0 & 0 & $6(18.2 \%)$ & $9(40.9 \%)$ & & \\
\hline & Grade III & 0 & 0 & $1(3.1 \%)$ & $4(18.2 \%)$ & & \\
\hline
\end{tabular}


Table 5: Correlation between GFR and echocardiographic parameters in the CKD patients:

\begin{tabular}{|c|c|c|}
\hline \multirow[t]{2}{*}{ Variables } & \multicolumn{2}{|c|}{ GFR } \\
\hline & $\mathbf{R}$ & p-value \\
\hline EF & -0.01 & 0.46 \\
\hline LA size & -0.21 & $0.018 *$ \\
\hline DT time & 0.01 & 0.46 \\
\hline E/A & -0.19 & $0.029 *$ \\
\hline $\mathbf{E}$ & -0.49 & $<0.001^{*}$ \\
\hline MED E' & 0.13 & 0.099 \\
\hline E/MED E' & 0.42 & $<0.001 *$ \\
\hline LAT $\mathbf{E}^{\prime}$ & 0.30 & $0.001 *$ \\
\hline E/LAT E' & -0.53 & $<0.001 *$ \\
\hline Diastolic function & -0.54 & $<0.001 *$ \\
\hline
\end{tabular}

R: Pearson correlation; *: significant $p$ <0.05; EF: ejection fraction; LA: left atrium; DT: deceleration time; MED: medial; LAT: lateral.

\section{Discussion}

LV diastolic dysfunction is very common in renal patients even in absence of valve pathology, coronary artery disease and hypertension $\underline{(18, \underline{19})}$

It is an indicator of damage to the myocardium before heart failure becomes clinically apparent $\stackrel{(20)}{\text {. }}$.

The conventional PWD echocardiography depends on multiple factors that make this way inaccurate for the diagnosis of diastolic dysfunction. TDI is a non-invasive cardiac imaging technique, more independent to the loading conditions $\stackrel{(21)}{ }$.

Patients in this study were divided according to GFR into 4 groups; I) Group1: GFR 60-90 $\mathrm{mL} / \mathrm{min} / 1.73 \mathrm{~m} 2$, II) Group 2: GFR 30$60 \mathrm{~mL} / \mathrm{min} / 1.73 \mathrm{~m} 2$, III) Group 3: GFR 15$29 \mathrm{~mL} / \mathrm{min} / 1.73 \mathrm{~m} 2$, and IV) Group 4: GFR $<15 \mathrm{~mL} / \mathrm{min} / 1.73 \mathrm{~m} 2$ in addition to 20 healthy subjects (control group) (Table 1).

This study aimed to determine the prevalence of LV diastolic dysfunction in chronic kidney patients and to quantify the relation of $\mathrm{LV}$ diastolic dysfunction and CKD. 
In the current study there was high significant difference between the five groups regarding age while there was no significant difference regarding sex distribution (Table 2).

This was similar to a study done in 2013, where it proved that diastolic function is a strong predictor of mortality in patients with CKD. The researchers found that there was a significant difference regarding age while there was no significant difference regarding sex distribution ${ }^{(22)}$.

In contrast to another study, this studied diastolic heart failure versus diastolic dysfunction in chronic kidney patients. They found that no significant difference regarding age or sex distribution $\stackrel{(23)}{ }$.

This could be explained by different sample size in the present study.

In the current study there was no significant difference regarding hypercholesterolemia, while there was significant difference regarding smoking, diabetes, hypertension and BMI (Table 2).

This was similar to another research performed in 2009, which studied LV diastolic dysfunction in the early stage of CKD, this study found that no significant difference between CKD and non CKD patients regarding hypercholesterolemia $\stackrel{(24)}{ }$. Also to the study done in 2010 which found that there was significant difference regarding BMI ${ }^{(23)}$. While it was in contrast to the study done in 2013, and proved that no significant difference was found regarding $\mathrm{DM}^{(22)}$.

This could be explained by different sample size of diabetic patient in the present study and other studies

In the current study there was significant difference between five groups regarding LA size, DT time, E/A, E, MED E', E/MED E', Lat E', EF and E/LAT E' (Table 3).

This was similar to the study done by a group of researchers who studied 186 patients with CKD obtaining TDI, they found that there was significant difference regarding $\mathrm{E} / \mathrm{e}^{\prime}$ ratio which correlated with cardiovascular event (25).

Some other researchers studied LV diastolic dysfunction in the early stage of CKD. They concluded that there was a significant difference between CKD and non CKD patients regarding DT time, E/A, E, MED E', E/MED E', Lat E' and E/LAT E', on the other hand they disagreed with us as there was no significant difference regarding ejection fraction $\stackrel{(24)}{ }$

In the current study, comparison of the GFR groups regarding grades of diastolic dysfunction; there was high significant difference between the four groups as grades 
of diastolic dysfunction was increased among patients of group 3 and group 4 (Table 4).

This was similar to a previous study whicho found that there was correlation between cardiovascular disease with advanced CKD (22).

The limitations in our study included i) A relatively limited number of patients were included in this study and this was responsible for some results being statistically non-significant, ii) The coronary artery disease (CAD) was ruled out only according to history, physical examination, ECG and echocardiography. More sensitive methods like stress tests, CT angiography and conventional angiography were not performed, so may be some patients with CAD were inadvertently included in the study.

So, we recommend for more trials on larger sections of CKD patients with new imaging techniques and other parameters for more accurate assessment of LV diastolic function.

\section{Conclusion}

LV diastolic dysfunction accompanies patients with $\mathrm{CKD}$, so all renal patients should undergo a routine echocardiography, putting in consideration that TDI is a very useful tool to un-mask the $\mathrm{LV}$ diastolic dysfunction.

\section{References}

1. Ceia F, Fonseca C, Mota T, Morais H, Matias F, De Sousa A, et al. Prevalence of chronic heart failure in Southwestern Europe: the EPICA study. European Journal of Heart Failure 2002;4(4):5319.

2. Daly R. Heart Failure with Preserved Left Ventricular Ejection Fraction. Topol and Griffin's Manual of Cardiovascular Medicine. 3rd ed. Philadelphia: Lippincott Williams and wilkins; 2009. p. 122.

3. Redfield MM. Heart Failure with Normal Ejection Fraction. Braunwald's Heart Disease: A Textbook of Cardiovascular Medicine: Elsevier 2012; p. 586-600.

4. Lau E, Tang W. Heart Failure with Preserved Ejection Fraction and Restrictive Cardiomyopathy. Topol and Griffin's Manual Of Cardiovascular Medicine 2013. 4th ed. Philadelphia: Lippincott Williams and Wilkins; p. 150.

5. Hunt SA. ACC/AHA 2005 Guideline Update for the Diagnosis and Management of Chronic Heart Failure in the Adult: A Report of the American College of Cardiology/American Heart Association Task Force on Practice Guidelines (Writing Committee to Update the 2001 Guidelines for the Evaluation and Management of Heart Failure): Developed in Collaboration With the American College of Chest Physicians and the International Society for Heart and Lung Transplantation: Endorsed by the Heart Rhythm Society. Circulation 2005; 112(12):el54-e235. 
6. Poirier P, Gameau C, Bogaty P, Nadeau A, Marois L, Brochu C, et al. Impact of left ventricular diastolic dysfunction on maximal treadmill performance in normotensive subjects with well-controlled type 2 diabetes mellitus. The American Journal of Cardiology 2000;85(4):4737.

7. McCray R, Francis G. Diagnosis and Management of Heart Failure. In: Robert A, Richard A, Valentin F, editors. Hurst's the Heart Manual of Cardiology 2009. 12th ed: McGrowHill; p. 231.

8. Braz JC, Gregory K, Pathak A, Zahau W, Sahin $\mathrm{B}$, Klevitsky R, et al. PKC-a regulates cardiac contractility and propensity toward heart failure. Nature Medicine 2004; 10(3):248-54.

9. Cerasola G, Nardi E, Palermo A, Mule G, Cottone S. Epidemiology and pathophysiology of left ventricular abnormalities in chronic kidney disease: a review, mortality;12:15.

10. Levey AS, Coresh J, Balk E, Kausz AT, Levin A, Steffes MW, et al. National Kidney Foundation Practice Guidelines for Chronic Kidney Disease: Evaluation, Classification, and Stratification. Annals of Internal Medicine 2003; 139(2): 137.

11. James PA, Oparil S, Carter BL, Cuchman W, Himmelfarb C, Handler J, et al. 2014 evidencebased guideline for the management of high blood pressure in adults: report from the panel members appointed to the Eighth Joint National Committee (JNC 8). JAMA 2014;311:507-520.

12. American Diabetes A. Diagnosis and classification of diabetes mellitus. Diabetes Care 2014;37 Suppl 1:S81-90.
13. Bays HE, Jones PH, Orringer CE, Brown W, Jacobson T. National Lipid Association Annual Summary of Clinical Lipidology 2016. J Clin Lipidol 2016;10:S1-43.

14. El Missiri A, El Meniawy K, Sakr S, EldeenMohameda A. Normal reference values of echocardiographic measurements in young egyptian adults. Egypt Heart J 2016;68:209-215.

15. Marwick T. Transthoracic anatomy and pathology: chambers and vessels. Oxford Specialist Handbooks in Cardiology, Echocardiography. 2nd ed: Oxford University Press; 2012. p. 191.

16. Nagueh SF. Tissue Doppler Imaging Predicts the Development of Hypertrophic Cardiomyopathy in Subjects With Subclinical Disease. Circulation. $2003 ; 108(4): 395-8$.

17. Connolly HM, Oh JK. Echocardiography. Braunwald's Heart Disease: A Textbook of Cardiovascular Medicine: Elsevier; 2012. p. 20076.

18. Ha J-W, Oh JK, Redfield MM, Ujino K, Seward JB, Tajik AJ. Triphasic mitral inflow velocity with middiastolic filling: clinical implications and associated echocardiographic findings. Journal of the American Society of Echocardiography. 2004; 17(5):428-31.

19. Oguzhan A, Arm H, Abaci A, Topsacal R, Eryol N, Ozdogru I, et al. Preload Dependence of Doppler Tissue Imaging Derived Indexes of Left Ventricular Diastolic Function. Echocardiography. 2005;22(4):320-5.

20. de Almeida EAF, de Oliveira El, Lopes JA, Almeida AG, Lopes MG, Prata MM. Diastolic Function in Several Stages of Chronic Kidney 
Disease in Patients with Autosomal Dominant Polycystic Kidney Disease: A Tissue Doppler Imaging Study. Kidney and Blood Pressure Research. 2007;30(4):234-9.

21. Kazik A, Wilczek K, Polonski L. Management of diastolic heart failure. Cardiology journal. 2010;17(6):558-65.

22. Farshid A, Pathak R, Shadbolt B, Arnolda L, Talaulikar T. Diastolic function is a strong predictor of mortality in patients with chronic kidney disease. BMC Nephrology. 2013; 14(1).

23. Victor BM, Barron JT. Diastolic Heart Failure Versus Diastolic Dysfunction: Difference in
Renal Function. Clinical Cardiology. 2010;33(12):770-4.

24. Otsuka T, Suzuki M, Yoshikawa H, Sugi K. Left ventricular diastolic dysfunction in the early stage of chronic kidney disease. Journal of Cardiology. 2009;54(2): 199-204.

25. Kim MK, Kim B, Lee JY, Kim JS, Han BG, Choi S, et al. Tissue Doppler-derived E/e' ratio as a parameter for assessing diastolic heart failure and as a predictor of mortality in patients with chronic kidney disease. The Korean Journal of Internal Medicine. 2013;28(1 ):35.

To cite this article: Shady Elhusseiny. Assessment of Left Ventricle Diastolic Dysfunction in Chronic Kidney Disease Patients. BMFJ 2021; 38(2):474-487, DOI: 10.21608/bmfj.2021.32804.1275 